\title{
Análise da produção científica brasileira em perícia contábil: mapeamento de 27 anos de pesquisa
}

\section{Analysis of Brazilian scientific production in forensic accounting: mapping for 27 years of research}

\author{
Pedro Paulo Garcia da Rosa ${ }^{1}$, Ducineli Régis Botelho ${ }^{2}$
}

\section{Resumo}

\begin{abstract}
A pesquisa objetiva analisar a produção científica brasileira em perícia contábil, sob o enfoque da Lei de Lotka, no período entre 1989 e 2015. Foi realizada uma pesquisa documental na plataforma eletrônica WEBQUALIS, do portal CAPES. Foram identificados 38 artigos publicados em 15 periódicos que atenderam aos critérios estabelecidos na pesquisa. Como ferramenta para análise da produção científica foi utilizada a lei bibliométrica de Lotka. Percebeu-se que apenas 10,53\% dos artigos foram produzidos por autoria individual, os $89,47 \%$ restantes foram produzidos por coautorias, não havendo indicação se existia autor principal nas publicações, sugerindo a confirmação e a aplicação dessa Lei à pesquisa. Quanto à produção de artigos, houve um aumento significativo no período do ano 2006 a 2015, representando 89,47\%, do total dos estudos identificados. Sugerem-se estudos mais aprofundados sobre o crescimento do fenômeno das coautorias e seu enquadramento nas leis bibliométricas para fins de análise. Propõem-se, também, estudos sobre a aplicação das demais leis da bibliometria nos artigos sobre perícia contábil, para serem observados os demais aspectos da produção científica nessa área, bem como, ainda, em função da existência de poucos trabalhos de pesquisa em perícia contábil, estudos para apresentar os motivos dessa ocorrência.
\end{abstract}

Palavras-chave: Bibliometria. Lei de Lotka. Produção científica. Perícia contábil. Brasil.

\footnotetext{
${ }^{1}$ Graduação em Ciências Contábeis pela Universidade de Brasília (UnB), Campus Universitário Darcy Ribeiro, Brasília, Distrito Federal, Brasil. E-mail: pgarciadarosa1968@gmail.com

${ }^{2}$ Doutorado em Ciências Contábeis pelo Programa Multi-institucional e Inter-regional de Pós-graduação em Ciências Contábeis da UnB, UFPB e UFRN, Brasil. Professora do Departamento de Ciências Contábeis e Atuariais da Universidade de Brasília, Brasília, Distrito Federal, Brasil. E-mail: ducineli@unb.br
} 


\begin{abstract}
The research aims to analyze the Brazilian scientific production in forensic accounting, under the Lotka Law approach, between 1989 and 2015. A documentary research was carried out on the electronic platform WEBQUALIS, of the CAPES portal. Thirty-eight articles were published in fifteen journals that met the criteria established in the research. As a tool for the analysis of scientific production, the bibliometric Law of Lotka was used. It was noticed that only $10.25 \%$ of the articles were produced by individual authorship, the remaining $89.74 \%$ were produced by co-authors, and there was no indication if there was a main author in the publications, obtaining results that suggest the confirmation and the application of this Law to the present work. As for the production of articles, there was a significant increase in the period from 2006 to 2015 , accounting for $89.47 \%$ of the total of the studies identified. More in-depth studies on the growth of co-authoring phenomena and their framing in bibliometric laws for analysis purposes are suggested. We also propose studies on the application of the other bibliometrics laws in the articles on forensic accounting, in order to be able to observe the other aspects of scientific production in this area, as well as due to the existence of few research studies in forensic accounting, studies to present the reasons for this occurrence.
\end{abstract}

Keywords: Bibliometrics. Law of Lotka. Scientific production. Forensic accounting. Brazil.

\section{Introdução}

Para Niyama e Silva (2013), a contabilidade, num sentido amplo, é uma Ciência Social Aplicada e tem como essência o estudo do patrimônio das organizações. Por isso, ela é fortemente influenciada pelo ambiente em que atua. As práticas contábeis em vigor acabam abarcando as diferenças históricas, os valores culturais e as estruturas políticas, legais e econômicas de cada país. Os princípios e as práticas contábeis podem ser diferentes de um país para outro.

Por suavez, Souza, Kowalskie Beuren(2015) entendem a contabilidade como provedora de informações econômico-financeiras, geradas pelo sistema de informação sob sua responsabilidade, e se relaciona com inúmeras áreas do conhecimento. Esse caráter interdisciplinar sugere que outras ciências influenciam a Ciência Contábil que, por sua vez, também exerce influência sobre outros campos científicos. Na mesma linha de raciocínio, localiza-se a abordagem de Riccio, Mendonça Neto e Sakata (2007) e sua afirmação de que as Ciências Sociais são formadas por vários campos de conhecimento, o que dá o caráter de interdisciplinaridade, ou seja, conceitos e teorias de diferentes disciplinas integram-se entre si, formando uma unidade que forma uma nova área do conhecimento. Essa é uma essência que dá a existência à contabilidade e a sua dinâmica.

$\mathrm{Na}$ visão de Trivinos (1987), o enfoque sistêmico parte do pressuposto que há inúmeras interligações internas na área de conhecimento pesquisada, porém, percebem-se muitas conexões com o mundo externo dessa área.

Essas conexões de uma Ciência Social como as Ciências Contábeis, credenciaram-na a atuar em vários campos, sempre se utilizando de ferramentas interdisciplinares como é o caso de sua subárea, a perícia contábil, que se utiliza de conhecimentos característicos de várias outras áreas, como por exemplo, a informática, a matemática, o direito e várias outras, tendo como foco contribuir para a solução de muitos dos inevitáveis conflitos advindos da convivência humana.

No estudo de Brandimiiler (1996), é exposto que a perícia tem como motivador primordial a requisição formal, que pode advir tanto de uma divergência de interesses fruto de um direito reclamado, como pode ter origem em investigações prévias do Ministério Público, na apuração dos fatos em demandas conflituosas; por exemplo, nas relações de trabalho, como acidentes no local de trabalho e doenças ocupacionais.

Outro tipo de perturbação da ordem social que se julga de alta relevância são os crimes 
tributários, os quais para Guimarães (2014) atingem de forma negativa o conjunto da sociedade, quase que de forma imperceptível.

Guimarães (2014) afirma que a prova pericial é praticamente imprescindível na comprovação da ocorrência de crime tributário, devendo, sempre que possível, o laudo ou relatório pericial abranger o papel desempenhado por cada envolvido, autores, coautores e partícipes, o "modus operandi" adotado pela organização, a fraude ocorrida e os outros meios utilizados, montante e momento da ocorrência da sonegação.

Conforme aumenta a ascendência do crime organizado no tecido social do Brasil e do mundo, proporcionalmente utilizam-se e se modernizam ainda mais as técnicas de perícia criminal para combatê-lo. A perícia criminal contábil é uma importante ferramenta na obtenção de provas para coibir a atuação dessas organizações criminosas.

Dessa forma, percebe-se que a perícia contábil é uma ferramenta, indubitavelmente, necessária e contributiva para a melhoria das relações sociais e negociais.

Considerando esse contexto, a perícia contábil, cada vez mais, tem sido objeto de estudo de pesquisadores que realizam seus trabalhos com o fim de produzir conhecimento científico nesse campo e consequentemente acabam demonstrando sua importância à comunidade acadêmica e a outros pesquisadores interessados por meio de publicações científicas nos periódicos. Corroborando esse raciocínio, Araújo e Alvarenga (2011) observam que muito se tem discutido sobre a tarefa de mensurar, caracterizar, e avaliar a ciência, ou seja, quantificar o resultado da atividade intelectual de pesquisadores e estudiosos que têm seu produto apresentado de diversas maneiras. Produção intelectual, produção acadêmica, produção do conhecimento e produção científica são terminologias presentes na literatura e utilizadas no meio acadêmico com o mesmo significado visando objetivos idênticos.

Assim, levando em conta a importância da atividade de pesquisa científica, da produção do conhecimento e sua disseminação, surge a seguinte pergunta de pesquisa: "do ponto de vista da bibliometria, qual é o cenário da produção científica brasileira em perícia contábil no período de 1989 a 2015?".

Uma das formas utilizadas pelos autores de partilhar o conhecimento científico é a publicação das pesquisas e as consequentes análises e resultados obtidos pelos autores dos estudos, em periódicos especializados para atualização da comunidade interessada e pesquisadores num sentido mais amplo. Dessa forma, segundo Alvarado e Oliveira (2001), os artigos publicados em periódicos formam um volume significativo de informações produzidas em determinado círculo científico e, assevera ainda que, os novos autores sentem a necessidade de buscar seu lugar na comunidade de disseminadores do conhecimento científico. Destarte, a motivação para publicar em um ritmo acelerado e obter o julgamento de seus pares advém da vontade de melhorar seu posicionamento na hierarquia dos produtores de escritos científicos.

A partir da produção científica e sua publicação em periódicos especializados é possível analisar entre outros dados o interesse de pesquisadores em desenvolver estudos em determinada área do conhecimento.

Neste caso, especificamente, será estudado qual o quantitativo de autores que produzem artigos científicos em perícia contábil e o volume de trabalhos por eles produzidos. $\mathrm{Na}$ análise a que se dispõe a presente pesquisa, considera-se a possibilidade de que os autores mais produtivos e, consequentemente, mais conhecidos formem um pequeno e seleto grupo; já por outro lado, poderá haver outro grupo de autores que formem um grande grupo com apenas um ou com poucos artigos publicados. Assim, justifica-se a pesquisa com a finalidade de verificar se há uma estratificação na produção científica da área em foco.

O objetivo desse artigo é analisar, sob o enfoque bibliométrico da Lei de Lotka, a produção científica em perícia contábil no Brasil, no período de 1989 a 2015.

As delimitações para proceder às buscas na referida plataforma consideraram os periódicos que estão inseridos na área de avaliação Administração 
Pública e de Empresas, Ciências Contábeis e Turismo na CAPES e deviam estar classificados no quadriênio 2013-2016. Foram pesquisadas todas as estratificações de $\mathrm{A} 1 \mathrm{a} \mathrm{C}$, considerando todos os periódicos aceitos na plataforma WEBQUALIS, disponibilizada no portal eletrônico da CAPES. O interstício de tempo pesquisado foi do ano de 1989 ao ano de 2015.

Para a busca de artigos científicos em cada revista especializada da amostra, com Qualis, utilizou-se as seguintes palavras-chave: perícia, contábil, perito, exame, laudo e diligências, considerando a opinião de Barba (2003), onde afirma que: "(i) o título é uma frase que encabeça o artigo científico e tem o objetivo de otimizar o fluxo comunicativo da ciência, se esperando que seja um bom resumo do texto; e (ii) as palavras-chaves devem destacar os pontos em que o trabalho se conecta com a disciplina" (apud MELLO et al., 2017 p. 52).

No Quadro 1, estão listados os periódicos pesquisados que atenderam aos critérios estabelecidos, em ordem crescente de produtividade.

Quadro 1 - Periódicos pesquisados.

\begin{tabular}{|c|c|c|c|}
\hline Periódicos & Artigos & Estrato & Períodos de publicação \\
\hline $\begin{array}{l}\text { Contexto: Revista do Núcleo de Estudos } \\
\text { e Pesquisas em Contabilidade }\end{array}$ & 1 & B3 & $2^{\circ}$ Sem. 2001 - Maio/Ago. 2015 \\
\hline Revista Contemporânea de Contabilidade & 1 & B1 & Jan./Jun. 2004 - Maio/Ago. 2015 \\
\hline Revista de Educação e Pesquisa em Contabilidade & 1 & B3 & Jan. 2007 - Dez. 2015 \\
\hline Revista de Gestão e Contabilidade da UFPI & 1 & BA & Jan./Jun. 2014 - Jul./Dez. 2015 \\
\hline Revista de Informação Contábil (UFPE) & 1 & B5 & Set. 2007 - Abr./Jun. 2014 \\
\hline Revista Enfoque: Reflexão Contábil & 1 & $\mathrm{~B} 1$ & 2005 - Set./Dez. 2015 \\
\hline Revista de Contabilidade da UFBA & 2 & B4 & Set./Dez. 2007 - Set./Dez. 2015 \\
\hline $\begin{array}{l}\text { Revista de Contabilidade do Mestrado } \\
\text { de Ciências Contábeis da UERJ }\end{array}$ & 2 & B5 & 1995 - Maio/Ago. 2015 \\
\hline Revista Sociedade, Contabilidade e Gestão & 2 & B3 & Jul. 2006 - Ago. 2015 \\
\hline Revista UNEMAT de Contabilidade & 2 & B4 & $2012 / 1-2015$ \\
\hline Revista Catarinense da Ciência Contábil & 4 & $\mathrm{~B} 1$ & 2001 Ed. Especial - Set./Dez. 2015 \\
\hline Revista Contabilidade Vista \& Revista & 5 & $\mathrm{~B} 1$ & Out. 1989 - Set./Dez. 2015 \\
\hline Revista Pensar Contábil & 6 & B4 & 2001 - Set./Dez. 2015 \\
\hline Revista Brasileira de Contabilidade (RBC - CFC) & 9 & $\mathrm{C}$ & Jan./Fev. 2006 - 2015 \\
\hline Total de artigos pesquisados & 38 & & \\
\hline
\end{tabular}

Fonte: CAPES (2019)

\section{Referencial Teórico}

\section{Aspectos preliminares sobre \\ o conhecimento cientifico}

É inegável o crescimento das pesquisas científicas na atualidade; também houve um aumento, paralelamente a isso, da produção literária que repercute essa expansão. Há muito interesse de pesquisadores em ter uma maior compreensão dessa situação, segundo Alvarado e Oliveira (2001), uma das questões a serem estudadas são os motivos que levam os cientistas a publicar trabalhos escritos. Na visão de Ziman (1979), “a função do cientista é produzir e publicar trabalhos originais, comunicar a seus pares, e assim contribuir para o conhecimento público" (apud ALVARADO; OLIVEIRA, 2001, p. 4).

Na visão de Ferrari (1971) a finalidade da pesquisa científica é a busca de um conhecimento 
específico. Existem, entretanto, as ciências formais como a lógica e a matemática, por outro lado as ciências factuais, que são empíricas e estudam os seres, as relações humanas e todas as suas consequências, em síntese, eventos que possam ser observados e experimentados. Em seu estudo sobre as ciências, Kuhn (2007) afirma que o conhecimento é o resultado do processo neurológico que transforma estímulos em sensações e tem como motor transmissor a educação; esse conceito teve que vencer embates históricos a nível de grupo através do método de tentativas; não é perene, pois, pode ser revisto.

As ciências factuais, conhecidas também como materiais ou empíricas, são as que se preocupam com fatos, sucesso e processos. Precisam de observação, de experimentação, pois utilizam símbolos interpretados. As ciências factuais caracterizam-se por serem: racionais, analíticas, verificáveis, sistemáticas, falíveis e explicativas. Utilize-se a contabilidade como exemplo, enquanto Ciência Social Aplicada é uma ciência factual, desde quando o seu objeto de estudo é o Patrimônio que carece de interpretação racional, sistemática, analítica, verificável e explicativa. Segundo Trivinos (1987), uma das contribuições do positivismo lógico foi a formulação do princípio da verificação ou a conhecida demonstração da verdade, através do experimento até a comprovação final. Se a teoria ficasse validada através da experimentação, essa seria considerada científica, senão seria refutada, considerada sem valor científico.

$\mathrm{Na}$ perspectiva de Oliveira et al. (2003), o conhecimento científico pode ser definido como real, quando é contingente, caso em que suas hipóteses podem ser postas à prova; sistemático, segue ordenação lógica; verificável, se a hipótese não for confirmada, é descartada como não científica; falível, não pretende ser o conhecimento absoluto, novas hipóteses podem surgir a todo momento; seu objeto é o real (factual). A ciência factual também é entendida como material ou empírica. Dessa forma, a Ciência Contábil é considerada factual, integrante do campo das
Ciências Sociais. Já o conhecimento formal lida com proposições abstratas, nesse campo se enquadra a lógica matemática.

Na opinião de Cervo e Bervian (2002), o conhecimento empírico dá ao homem a percepção dos entes, objetos, fatos e fenômenos e sua ordem aparente, explica a razão de ser das coisas e das pessoas. Já o conhecimento científico aprofunda mais a busca do saber, vislumbrando a compreensão além do ente, do objeto, do fato e do fenômeno, estudando sua estrutura, sua organização e funcionamento, sua composição, causas e leis.

No estudo de Theophilo e Iudícibus (2005), é citado que nos últimos anos são feitos bons trabalhos utilizando o método de estudo teóricoempírico, relevante para a contabilidade que trata da geração e divulgação de informações à sociedade.

$\mathrm{Na}$ opinião de Martins (1997 apud ZANCHET; MARQUES; MARTINS, 2011, p. 4) "as pesquisas de abordagem empiristas seguem por marcas experimentais ou quase experimentais com uso de pré-teste e pós-teste da amostra". Vislumbram utilizar nas Ciências Sociais, através de adaptações, os mesmos métodos das ciências naturais. "Os testes estatísticos são empregados na verificação de hipóteses de pesquisa e a causalidade é concebida como uma relação direta de causaefeito ou estímulo-resposta".

\section{Aspectos da bibliometria e Lei de Lotka}

O presente estudo visa um enfoque quantitativo utilizando a bibliometria, especificamente a Lei de Lotka, dos artigos científicos sobre perícia contábil publicados em periódicos especializados que disseminam o conhecimento.

Na definição de Lima (1986), a bibliometria se utiliza das técnicas estatísticas para analisar a produção científica, objetivando um recenseamento da literatura, já a cientometria, uma ciência métrica correlata à bibliometria, utiliza as técnicas estatísticas e matemáticas para avaliar a atividade científica considerando seu contexto sociológico. 
Segundo Vanti (2002), as aplicações das ciências métricas, em termos genéricos, são: identificar tendências e crescimento do conhecimento em uma determinada área; estudar dispersão e obsolescências da literatura científica; mensurar a cobertura das revistas científicas; identificar as revistas do núcleo de cada disciplina; identificar os usuários de uma disciplina; prever as tendências de publicação; prever a produtividade de autores individuais, organizações e países; medir o grau e padrões de colaboração entre autores; analisar os processos de citação e cocitação; determinar o desempenho dos sistemas de recuperação da informação; avaliar os aspectos estatísticos da linguagem, das palavras e das frases; avaliar a circulação e uso de documentos em um centro de documentação; medir o crescimento de determinadas áreas e o surgimento de novos temas.

$\mathrm{Na}$ opinião de Vanti (2002), os índices bibliométricos também são utilizados para avaliar a produtividade e a qualidade da pesquisa dos cientistas, por meio da medição com base nos números de publicações e citações dos diversos pesquisadores.

Segundo Araújo e Alvarenga (2011) a bibliometria, utiliza-se de técnicas estatísticas para avaliar a produção do conhecimento de uma determinada área e o resultados dessa análise evidenciam o índice de desenvolvimento dessa área do conhecimento humano.

Nesse contexto, a importância da aplicação da Lei de Lotka, na opinião de Guedes e Borschiver (2005), na gerência das informações e do conhecimento científico, considerando a sociedade tecnológica atual, se percebe na avaliação da produção dos autores, na demonstração dos maiores núcleos de pesquisa e áreas científicas mais consistentes e que, por isso, os autores destas áreas terão mais profusão na produção de textos científicos.

Segundo Alvarado e Oliveira (2001) e Guedes e Borschiver (2005), esse comportamento também é verificado na produção científica; uma hierarquia, uma estrutura estratificada. A Lei de Lotka pondera que poucos autores percebidos como de maior influência em um determinado assunto produzem muito, e muitos autores, vistos como de menor influência, produzem pouco.

Vanti (2002) define que a Lei de Lotka pretende medir a produtividade dos autores, levando em consideração o quanto os autores produzem em determinada unidade de tempo comparado aos seus pares de mesma área do conhecimento.

Conforme Lima (1986) e Araújo (2006), a Lei de Lotka foi estabelecida em 1926, tendo como princípio a Lei do Quadrado Inverso. A partir de então, muitas pesquisas foram realizadas com a finalidade de fazer verificações quanto à produção dos autores nos campos das mais variadas áreas do conhecimento, concordando com as conclusões propostas e as propagando, assim como, também levantando questionamentos ou propondo mudanças na Lei de Lotka. Já Alvarado e Oliveira (2001) mencionam os muitos trabalhos nesse sentido, em nível internacional, tendo como base de dados vários disseminadores como ISA, Library Literature, Current Contents, ERIC, PsycInfo, Compendex, Agrícola, Biosis, Inspec, Hapi, Dialog, Pascal, Uncover, Sociological Abstracts, Magazines \& Journals (MAGS), bem como as bases de dados bibliográficos do Cindoc (Espanha), Infobila (México) e Lici do Ibict (Brasil). Numerosas foram as pesquisas, porém, não chegando a conclusões definitivas sobre a validade dessa Lei bibliométrica e nem a sua negação.

Dessa forma, nos estudos pesquisados de Alvarado e Oliveira (2001), é demonstrado que o número de autores que fazem " $n$ " contribuições na pesquisa científica de uma área específica é de $1 \mid n^{2}$, daqueles que fazem uma só contribuição. O percentual dos autores que fazem apenas uma publicação é próximo de 60 por cento, princípio básico da Lei de Lotka.

\section{Metodologia}

Este estudo é uma pesquisa qualitativa, com abordagem exploratória, com enfoque bibliométrico sobre a produtividade dos autores de pesquisas científicas no campo da perícia 
contábil, no período de 1989 a 2015, sob a égide da Lei de Lotka.

Os procedimentos técnicos foram pesquisas documentais na plataforma WEBQUALIS, disponibilizada pelo portal eletrônico da CAPES, alusiva à área de avaliação - Administração Pública e de Empresas, Ciências Contábeis e Turismo da CAPES - para seleção das revistas especializadas da amostra, do quadriênio 2013-2016. Utilizaramse as seguintes palavras-chave para identificar os artigos científicos na área de interesse, coletados nas revistas especializadas - perícia, contábil, perito, exame, laudo e diligências - no período compreendido entre janeiro e julho de 2016.

\section{Perfil da Amostra}

Utilizando-se os critérios estabelecidos, foi possível mapear a quantidade de 14 periódicos, que retornaram às buscas efetuadas, na plataforma WEBQUALIS (da área de Administração Pública e de Empresas, Ciências Contábeis e Turismo da CAPES), nos quais se constatou uma quantidade de 38 artigos sobre perícia contábil, que serviram como objeto de análise. Fez-se uma breve análise dos periódicos com o objetivo de proporcionar uma visão mais abrangente das publicações na área de interesse.

Foram identificados 14 periódicos na área de pesquisa responsáveis pela publicação de 38 artigos sobre perícia contábil. Verifica-se que desse total, seis revistas publicaram um artigo cada, ou $42,85 \%$ dos periódicos foram responsáveis pela publicação de $15,78 \%$ dos artigos. Por outro lado, o periódico que mais publicou foi a Revista Brasileira de Contabilidade ( $R B C-C F C)$, contribuindo com a publicação recorde de nove artigos na área pesquisada, significando que $7,14 \%$ dos periódicos respondem por $23,68 \%$ das publicações. É também a revista que mais publicou um mesmo autor com seis publicações - considere-se que todas essas publicações foram em coautorias, representando $15,78 \%$ das publicações. A segunda revista mais produtiva foi a Revista Pensar Contábil, com seis artigos publicados, em termos percentuais $15,78 \%$ do total conforme demonstrado na Tabela 1.

Tabela 1 - Perfil da amostra.

\begin{tabular}{clcc}
\hline Ordem & \multicolumn{1}{c}{ Periódicos } & Artigos & Percentual artigo/periódicos \\
\hline 1 & Contexto: Revista do Núcleo de Estudos & 1 & $2,63 \%$ \\
& e Pesquisas em Contabilidade & 1 & $2,63 \%$ \\
3 & Revista Contemporânea de Contabilidade & 1 & $2,63 \%$ \\
4 & Revista de Educação e Pesquisa em Contabilidade & 1 & $2,63 \%$ \\
5 & Revista de Gestão e Contabilidade da UFPI & 1 & $2,63 \%$ \\
6 & Revista de Informação Contábil (UFPE) & 1 & $2,63 \%$ \\
7 & Revista Enfoque: Reflexão Contábil & 2 & $5,26 \%$ \\
8 & Revista de Contabilidade do Mestrado & 2 & $5,26 \%$ \\
9 & de Ciências Contábeis da UERJ & 2 & $5,26 \%$ \\
10 & Revista Sociedade, Contabilidade e Gestão & 2 & $5,26 \%$ \\
11 & Revista UNEMAT de Contabilidade & 4 & $10,52 \%$ \\
12 & Revista Catarinense da Ciência Contábil & 5 & $13,15 \%$ \\
13 & Revista Contabilidade Vista \& Revista & 6 & $15,78 \%$ \\
14 & Revista Brasileira de Contabilidade (RBC - CFC) & 9 & $23,68 \%$ \\
\hline
\end{tabular}

Fonte: Autores 
Verifica-se pela Tabela 1 a disparidade entre os disseminadores das pesquisas em perícia contábil, demonstrando que há uma hierarquia entre os periódicos, sendo que poucos periódicos centralizam as publicações do conhecimento, enquanto poucas publicações ficam divididas entre os demais.

A Revista Contabilidade Vista \& Revista é o periódico pesquisado mais antigo, sendo encontradas publicações no meio virtual desde outubro de 1989. Porém, o primeiro artigo sobre perícia contábil encontrado foi somente no ano de
1995, na Revista de Contabilidade do Mestrado de Ciências Contábeis da UERJ. Quanto à produtividade anual, nota-se que os anos de 2008 e 2010 foram os mais produtivos com seis publicações $(15,78 \%)$ cada um. Percebe-se também que, excetuando-se os anos de 1995 e 1999, todos os demais foram produzidos dos anos 2000, até a atualidade, evidenciando que a produção de pesquisas em perícia contábil publicada em periódicos especializados é relativamente recente como verifica-se no Gráfico 1.

Gráfico 1 - Evolução temporal das publicações dos periódicos.

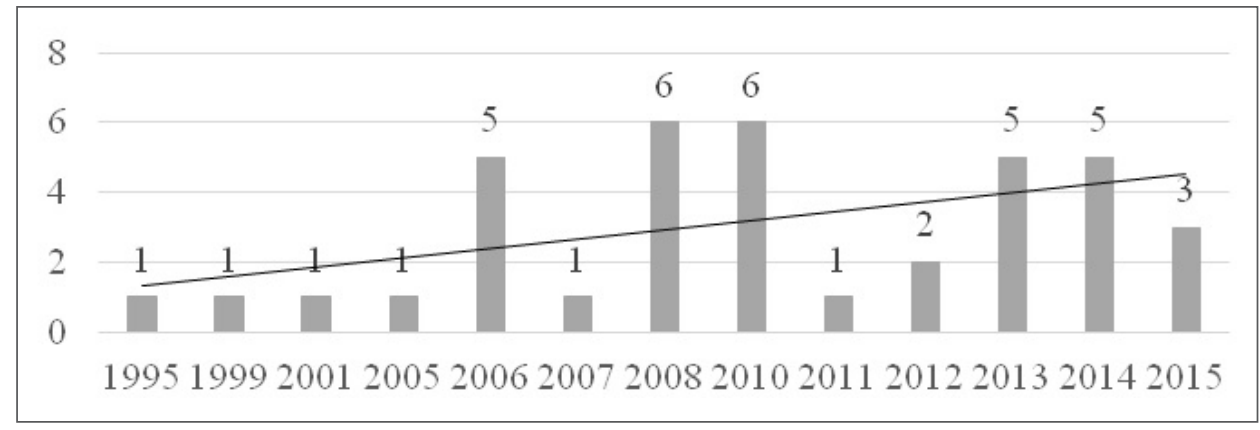

Fonte: Autores

Verifica-se no Gráfico 1 uma linha de tendência linear crescente, considerando-se todo período pesquisado. Porém, pode-se verificar certa irregularidade no quantitativo publicado na linha do tempo com altos e baixos, no entanto, de 2006 até a atualidade tem-se uma média de 3,89 artigos por ano, deixando claro que os índices de produção científica aumentaram significativamente, em relação ao período anterior. Deduz-se disso que as pesquisas na área da perícia contábil estão a caminho do amadurecimento científico, porém, ainda falta muito trabalho da comunidade contábil para atingir esse objetivo.

\section{Discussões e Análises dos Resultados}

Do quantitativo de 38 artigos identificados na área de interesse, 10 artigos, ou seja, 26,31\% tiveram a participação colaborativa repetida de um mesmo autor, não constando nenhuma publicação individual sua, o mesmo ocorrendo com outros quatro autores que produziram três artigos cada, também em forma colaborativa, resultando em 12 artigos, considerando a produtividade desses autores têm-se o percentual de $63,15 \%$, do total dos artigos pesquisados foram produzidos por cinco autores ou $5,37 \%$ do total dos autores pesquisados. Ressaltese que em termos de produção individual foram localizados quatro artigos, produzidos por um único autor cada, dessa forma verificou-se que 4,30\% dos autores produziram um artigo, individualmente, resultando $10,53 \%$ do total. Em função disso, obviamente, foi percebido que 34 artigos, ou seja, $89,47 \%$ foram produzidos em coautorias.

Em função do fenômeno do alto índice de coautorias, os dados obtidos foram organizados para fins de análise da seguinte forma: considerando a coprodução dos autores que mais produziram (cinco autores - 22 artigos), considerando-os como autor principal, acrescido à produção unicamente individual citada (quatro autores - quatro vezes), obtém-se que nove autores $(9,68 \%)$ produziram 
ou participaram como principal em 26 artigos, ou $68,42 \%$ do total produzido.

Demonstra-se, na Tabela 2, a produtividade individual dos autores, sendo que quatro autores produziram quatro artigos; coautoria 1 , um autor participou em 10 artigos; coautoria 2, quatro autores participaram em três artigos cada um; coautoria 3, sete autores produziram dois artigos cada; coautoria 4, 78 autores produziram um artigo cada. É importante esclarecer que, por ocasião da pesquisa não foi percebido qual seria a ordem de importância dos autores que subscreveram os artigos.

Tabela 2 - Produtividade dos autores.

\begin{tabular}{ccc}
\hline Formas de atuação & Autores & Artigos \\
\hline Individuais & 4 & 4 \\
Coautoria 1 & 1 & 10 \\
Coautoria 2 & 4 & 3 \\
Coautoria 3 & 7 & 2 \\
Coautoria 4 & 78 & 1 \\
\hline Total & 94 & 38 artigos produzidos \\
\hline
\end{tabular}

Fonte: Autores

Dessa forma, evidencia-se na Tabela 2 a alta produtividade de poucos autores, incluídas coautorias e considerando os autores, cujos nomes aparecem mais vezes como principais por não se perceber explicitados na pesquisa, e quais autores são principais, se existirem autores principais.

A Tabela 3 demonstra em percentual os dados de participação dos autores na produção científica em perícia contábil na amostra estudada.

Tabela 3 - Participação na produção dos artigos.

\begin{tabular}{ccc}
\hline Formas de atuação & Autores \% & Artigos \% \\
\hline Individuais & 4,26 & 10,53 \\
Coautoria 1 & 1,06 & 26,32 \\
Coautoria 2 & 4,26 & 7,89 \\
Coautoria 3 & 7,45 & 5,26 \\
Coautoria 4 & 82,98 & 2,63 \\
\hline Total & 100 & 38 artigos \\
\hline
\end{tabular}

Fonte: Autores

$\mathrm{Na}$ forma percentual, percebe-se a razão inversamente proporcional entre a alta produtividade de poucos autores em relação a grande quantidade de autores com pouca produtividade, confirmando a Lei de Lotka.
Gráfico 2 - Participação na produção dos artigos.

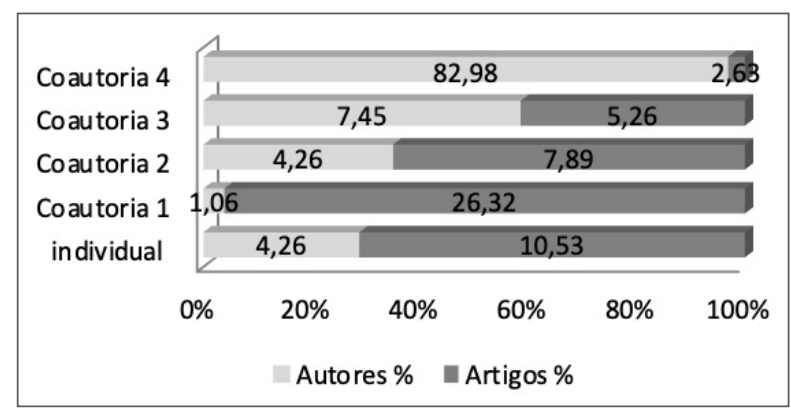

Fonte: Autores 
Efetuando-se uma adição simples dos percentuais dos autores que produziram mais de um artigo, como se verifica no Gráfico 2, e considerando-se esses autores como principais para efeito de análise, chega-se a $17,02 \%$, enquanto o somatório que correspondente à produtividade desses autores resulta em 50\%. Como preconiza a Lei de Lotka, existe um núcleo de autores que é muito produtivo e um grupo disperso de vários autores que muito pouco produz.

$\mathrm{Na}$ Tabela 4, demonstra-se o total de participações de cada autor, considerando cada um como autor principal de cada um dos artigos identificados, em função de que não há indicação da classificação dos autores. Tendo em vista que o total de autores soma o montante de 94 e seguindo-se o critério acima, tem-se que o total de participações resulta em 118 contribuições.

Tabela 4 - Participações na produção dos artigos.

\begin{tabular}{lccc}
\hline Forma de atuação & Quantitativo de autores & Publicações por autor & Total de participações \\
\hline Autoria individual & 4 & 4 & 4 \\
Coautoria 1 & 1 & 10 & 10 \\
Coautoria 2 & 4 & 3 & 12 \\
Coautoria 3 & 7 & 2 & 14 \\
Coautoria 4 & 78 & 1 & 78 \\
\hline Total & 94 & & 118 \\
\hline
\end{tabular}

Fonte: Autores

Mais uma vez denota-se que há uma comprovação da Lei de Lotka, adotada para analisar a produtividade dos autores nesta área de interesse. Verifica-se que 78 autores de um total de 94 autores que subscreveram os artigos pesquisados, resultando no expressivo percentual de $82,98 \%$ dos autores, participaram uma vez apenas na produção em questão. Por outro lado, 16 autores contribuíram com as pesquisas com o expressivo número de 40 participações do total de 118 participações. No Gráfico 3, verifica-se os percentuais de cada grupo demonstrado na Tabela 4.

Gráfico 3 - Participações na produção dos autores.

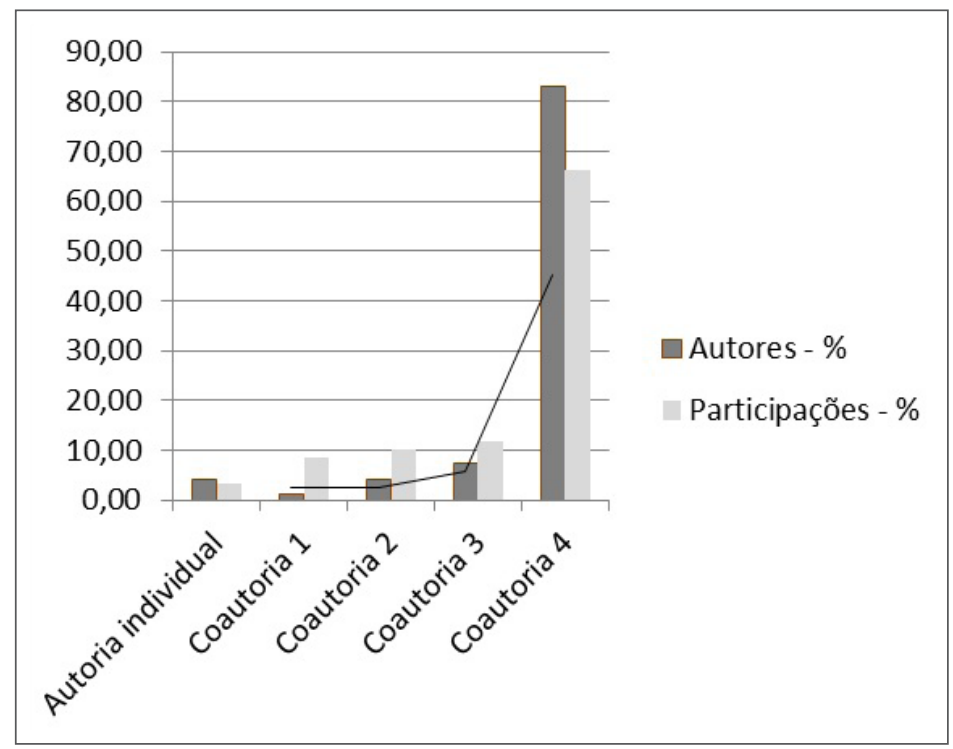

Fonte: Autores 
Nota-se no Gráfico 3, no item coautorias 4, na coluna que representa o percentual de autores $(82,98 \%)$, e suas contribuições para as pesquisas alcançaram um percentual de $66,10 \%$ das participações, porém com uma participação individual apenas. As demais colunas dos autores são sempre menores que as colunas que representam as participações, sugerindo que poucos autores produziram muito em relação a muitos autores que produziram pouco. A exceção é a primeira coluna, pois o número de autores individuais é igual ao número de participações; registre-se essa baixa produtividade individual dos autores.

Silva et al. (2018) identificaram 24 artigos na temática de perícia contábil no período de 2006 a 2015. Enquanto, o estudo de Taveira et al. (2013) revelou apenas 30 artigos científicos para o período de 1999 a 2011. Portanto, apesar da escassez de estudos bibliométricos na área de perícia contábil, as pesquisas corroboram os resultados do presente estudo. Para maior maior detalhamento, a Tabela 5 destaca os autores que participaram em mais de um artigo científico em perícia contábil no período analisado.

Tabela 5 - Autores mais produtivos.

\begin{tabular}{|c|c|}
\hline Autores & Quantitativo \\
\hline Idalberto José das Neves Júnior & 10 \\
\hline Ivam Ricardo Peleias & 4 \\
\hline Carlos Alberto Serra Negra & 3 \\
\hline Waldiney Marinho de Melo & 3 \\
\hline Elizabete Marinho Serra Negra & 2 \\
\hline Joana Darc Medeiros Martins & 2 \\
\hline Luiz Carlos Marques dos Anjos & 2 \\
\hline Marcelo Daia Barreto & 2 \\
\hline Marco Antonio Amaral Pires & 2 \\
\hline Martinho Maurício Gomes de Ornelas & 2 \\
\hline Vanderlei dos Santos & 2 \\
\hline Outros (autores com uma publicação cada) & 88 \\
\hline Total de autores & 122 \\
\hline
\end{tabular}

Fonte: Autores

Pode-se depreender da Tabela 5 que há um núcleo mais produtivo, sugerindo que poucos autores produziram muito em relação a muitos autores que produziram pouco, que é a essência ditada pela Lei de Lotka.

\section{Considerações Finais}

O objetivo desse artigo foi analisar, sob o enfoque bibliométrico da Lei de Lotka, a produção científica em perícia contábil no Brasil, no período de 1989 a 2015. Concluiu-se que a produtividade dos autores, no período que compreende os anos de 1989 a 2015, obteve um significativo aumento nos últimos anos.

Infere-se que a motivação para isso deva ser a maior importância que esta área assumiu nos últimos anos em função de um maior número de demandas sociais impostas pelas necessidades de cidadãos mais exigentes em relação a seus direitos, não obstante, a necessidade de estudos mais aprofundados sobre a questão.

De outra forma, constatou-se que não é uma produção muito expressiva, levando em conta que o período pesquisado foi de 27 anos, entre 1989 e 2015 , ou seja, $63,15 \%$, do total dos artigos 
pesquisados foram produzidos por cinco autores ou $5,37 \%$ do total dos autores pesquisados.

Em relação ao quantitativo de artigos publicados nos periódicos da área contábil, identificou-se que a Revista Brasileira de Contabilidade - RBC, do Conselho Federal de Contabilidade (CFC), e a Revista Pensar Contábil publicaram, juntas, 39,47\% dos artigos no período em questão. Infere-se, dessa forma, que também há um núcleo dos periódicos que mais produzem em relação aos demais. Pela análise dos resultados, percebeu-se que apenas 10,53\% dos artigos foram produzidos por autoria individual, os $89,47 \%$ restantes foram produzidos por coautorias, não havendo indicação se existia autor principal nas publicações. Quanto à produção de artigos, houve um aumento significativo no período do ano 2006 a 2015 , representando por $89,47 \%$, do total dos estudos identificados. Dessa forma, os dados foram analisados e submetidos ao princípio da Lei de Lotka, obtendo-se resultados que sugerem a confirmação e a aplicação dessa Lei ao presente trabalho.

Considerou-se que o fenômeno das coautorias é fator limitante para a aplicação da Lei de Lotka, pois para que essa Lei possa ser aplicada na análise dos dados foi necessário inferir que cada autor foi responsável pelo artigo em que participou. Outro fator limitante da pesquisa é o reduzido número de artigos, levando em conta o longo período analisado. Tendo em vista as questões acima, sugeremse pesquisas sobre o fenômeno das coautorias nas publicações científicas, podendo haver uma maior democratização no ensino e nas pesquisas científicas, o que ensejam mais participantes resultando na prática de coautorias. São importantes, também, estudos no sentido de como proceder ao enquadramento desse fenômeno nas leis da bibliometria. Sugerem-se pesquisas no sentido de esclarecer a existência de poucos trabalhos de pesquisa em perícia contábil, bem como estudos sobre a aplicação das demais leis da bibliometria nos artigos sobre perícia contábil.

\section{Referências}

ALVARADO, R. U.; OLIVEIRA, M. A. Produtividade dos autores na antropologia brasileira. DataGramaZero: Revista de Ciência da Informação, João Pessoa, v. 2, n. 6, 2001. Disponível em: https://bit.ly/2LBpv8Z. Acesso em: 6 fev. 2019.

ARAÚJO, C. A. Bibliometria: evolução histórica e questões atuais. Em Questão, Porto Alegre, v. 12, n. 1, p. 11-32, 2006. Disponível em: https://bit. ly/2zFIZH5. Acesso em: 30 jan. 2019.

ARAÚJO, R. F.; ALVARENGA, L. A. Bibliometria na pesquisa científica da pós-graduação brasileira de 1987 a 2007. Revista Eletrônica de Biblioteconomia e Ciência da Informação, Curitiba, v. 16, n. 31, 2011. Disponível em: https:// bit.ly/3fSwlF3. Acesso em: 24 jan. 2019.

BRANDIMIILER, P. A. Perícia judicial em acidentes e doenças do trabalho. São Paulo: SENAC, 1996.

CAPES. Avaliação. Plataforma sucupira. Disponível em: https://www.capes.gov.br/ avaliacao/plataforma-sucupira. Acesso em: 15 fev. 2019.

CERVO, A. L.; BERVIAN, P. A. Metodologia cientifica. 5. ed. São Paulo: Prentice Hall, 2002.

FERRARI, A. T. Metodologia e técnica da pesquisa social. 2. ed. Campinas: IPPACC, 1971. v. 1.

GUEDES, V. L. S; BORSCHIVER, S. Bibliometria: uma ferramenta estatística para a gestão da informação e do conhecimento, em sistemas de informação, de comunicação e de avaliação científica e tecnológica. In: CINFORM: ENCONTRO NACIONAL DE CIÊNCIA DA INFORMAÇÃO, 6., 2005, Salvador. Anais [...]. Salvador: UFBA, 2005. p. 1-18. Disponível em: https://bit.ly/2Z7YAK4.pdf. Acesso em: 15 fev. 2019.

GUIMARÃES, R. P. A auditoria e a perícia como instrumentos no combate aos crimes contra a ordem tributária. Conteúdo Jurídico, Brasília, 2014. Disponível em: https://bit.ly/367MB0k. Acesso em: 15 fev. 2019. 
KUHN, T. S. A estrutura das revoluções científicas. São Paulo: Perspectiva, 2007.

LIMA, R. C. M. Bibliometria: análise quantitativa da literatura como instrumento de administração em sistemas de informação. Ciência da Informação, Brasília, v. 15, n. 2, 1986. Disponível em: https:// bit.ly/3bE8S76. Acesso em: 15 fev. 2019.

MELLO, I. R.; BARBOSA, K. M. F.; DANTAS, J. A.; BOTELHO, D. R. 25 anos de publicação em auditoria: análise bibliométrica sob o ponto de vista da Lei de Lotka, Lei de Zipf e ponto de transição (T) de Goffman. Revista de Estudos Contábeis, Londrina, v. 8, n. 15, 2017. Disponível em: https:// bit.ly/2Z6wJK1. Acesso em: 15 fev. 2019.

NIYAMA, J. K.; SILVA, C. A. T. Teoria da contabilidade. 3. ed. São Paulo: Atlas, 2013.

OLIVEIRA, A. B. S.; CECONELLO, A. R.; BARBOSA, C. F.; CÉLICE, E. S.; KOUNROSAN, M. C.; DIGIORGI, W. A. B. Métodos e técnicas de pesquisa em contabilidade. São Paulo: Saraiva, 2003.

RICCIO, E. L. N.; MENDONÇA NETO, O. R.; SAKATA, M. C. G. Movimentos de teorias em campos interdisciplinares: a inserção de Michel Foucault na contabilidade. Revista Administração Contemporânea, Curitiba, v. 11, n. 2, 2007. Disponível em: https://bit.ly/2TeKGlH. Acesso em: 15 fev. 2019.

SILVA, B. B.; MOREIRA, W. S.; OLIVEIRA, J. G.; SOEIRO, T. M. Produção acadêmica sobre perícia contábil nos periódicos nacionais de contabilidade: uma análise do último decênio. Revista de Contabilidade da UFBA, Vale do Canela, v. 12, n. 2, 2018. Disponível em: https:// bit.ly/3e3NXML. Acesso em: 15 fev. 2019.

SOUZA, J. C.; KOWALSKI, F. D.; BEUREN, I. M. A filosofia em campos interdisciplinares: a inserção de Thomas S. Kuhn na contabilidade. In: SIMPÓSIO DE EXCELÊNCIA DA GESTÃO SEGeT, 3., 2015, Resende. Anais [...]. Resende: AEDB, 2015. p. 1-12. Disponível em: https://bit. ly/3dSxKtz. Acesso em: 15 fev. 2019.
TAVEIRA, L. D. B.; MEDEIROS, A. W.; CAMARA, R. P. B.; MARTINS, J. D. M. Uma análise bibliométrica dos artigos científicos em perícia contábil publicados entre os anos de 1999 a 2012. Revista de Contabilidade do Mestrado em Ciências Contábeis da UERJ, Rio de Janeiro, v. 18, n. 2, 2013. Disponível em: https://bit.ly/2zNEz0w. Acesso em: 15 fev. 2019.

THEOPHILO, C. R.; IUDÍCIBUS, S. Uma Análise crítico-epistemológica da produção científica em contabilidade no Brasil. Contabilidade, Gestão e Governança, Brasília, v. 8, n. 2, 2005. Disponível em: https://bit.ly/2zLd2Ng. Acesso em: 15 fev. 2019.

TRIVINOS, A. N. S. Introdução à pesquisa em ciências sociais: a pesquisa qualitativa em educação. São Paulo: Atlas, 1987.

VANTI, N. A. P. Da bibliometria à webometria: uma exploração conceitual dos mecanismos utilizados para medir o registro da informação e a difusão do conhecimento. Ciência da Informação, Brasília, v. 31, n. 2, 2002. Disponível em: https:// bit.ly/3dP9qsu. Acesso em: 15 fev. 2019.

ZANCHET, A.; MARQUES, C.; MARTINS, G. A. Epistemologia das abordagens metodológicas na pesquisa contábil: do normativismo ao positivismo. In: ENCONTRO NACIONAL DA ASSOCIAÇÃO NACIONAL DE PROGRAMAS DE PÓSGRADUAÇÃO EM ADMINISTRAÇÃO, 35., 2011, Rio de Janeiro. Anais [...]. Rio de Janeiro: ENANPAD, 2011.p. 1-17. Disponível em: https:// bit.ly/2y99X9B. Acesso em: 15 fev. 2019. 
Rosa, P. P. G.; Botelho, D. R. 